\title{
Removal of entrapped iron compounds in isothermally treated catalytic chemical vapor deposition derived multi-walled carbon nanotubes
}

\author{
J. Chen ${ }^{\text {a } *}$, A. Kuno ${ }^{\text {b }}$, M. Matsuo ${ }^{\text {b }}$, T. Tsukada ${ }^{\text {a }}$, T. Tamura ${ }^{\text {a }}$, K. Osato ${ }^{\text {a }}$ J. Y. Shan ${ }^{\text {a }}$, \\ F. Munekane ${ }^{\text {a }}$, Y. A. $\operatorname{Kim}^{c}$, T. Hayashi $^{\text {c }}$, and M. Endo ${ }^{\mathrm{c}}$ \\ a Nano Carbon Technologies Co., Ltd., 600 Tanaka-cho, Akishima-shi, Tokyo 196-8522, Japan \\ ${ }^{\mathrm{b}}$ Graduate School of Arts and Sciences, The University of Tokyo, 3-8-1 Komaba, Meguro-ku, \\ Tokyo 153-8902, Japan \\ ${ }^{c}$ Faculty of Engineering, Shinshu University, 4-17-1 Wakasato, Nagano-shi 380-8553, Japan
}

\begin{abstract}
We have monitored the compositional changes of the residual metallic compounds in isothermally treated catalytic chemical vapor deposition derived multi-walled carbon nanotubes systematically using ${ }^{57} \mathrm{Fe}$ transmission Mössbauer and X-ray fluorescence. The iron phases entrapped in the as-synthesized carbon nanotubes consist of $\gamma$-iron, $\alpha$-iron, $\mathrm{Fe}_{3} \mathrm{C}$ and $\mathrm{Fe}_{1-\mathrm{x}} \mathrm{S}$. The $\mathrm{Fe}_{1-\mathrm{x}} \mathrm{S}$ phase decomposes completely around $1500{ }^{\circ} \mathrm{C}$ while the iron carbide phase decomposes in the temperature range of $1500-2400{ }^{\circ} \mathrm{C}$. The obtained apparent activation energy of ca. 76 $\mathrm{kcal} / \mathrm{mol}$ suggests that the entrapped iron was removed via a diffusion process during thermal treatment.
\end{abstract}

*Corresponding author: Tel: +81 42549 2531; Fax: +81 425492533

E-mail address: j-chen@hodogaya.co.jp (J. Chen) 


\section{Introduction}

For the last decade, carbon nanotubes have attracted much attention from academics and industry [1-4], because their theoretically calculated and then experimentally confirmed excellent physicochemical properties [5-9] make them promising in various applications [10]. Most interest has been in the establishment of the cost-effective synthesis techniques for producing carbon nanotubes on a large scale. A floating reactant method based on the catalytic chemical vapor deposition (CCVD) method adopted by several companies enables multi-walled carbon nanotubes (MWCNTs) to be produced in a large quantity at a relatively low cost [11-14]. Unfortunately, the current largest obstacle for blocking the widespread use of carbon nanotubes is considered their potential toxic nature [15-18]. In general, dissolved metal elements are known to cause toxicity in live organs $[19,20]$. In addition, the metals in asbestos are reported to act as catalysts to create reactive oxygen compounds that damage DNA and other vital cellular components [15]. Recently, the remained metal particles entrapped in carbon tubes are considered to cause toxicity [18]. Therefore, high-temperature thermal treatment has been adopted industrially as a powerful post-treatment to improve structural integrity as well as remove the residual metal catalysts entrapped in CCVD-derived MWCNTs, effectively [21-23]. In our previous study [23] it has been revealed that the removal of iron catalysts entrapped in carbon nanotubes involved the decomposition of iron compound with sulfur around $1500{ }^{\circ} \mathrm{C}$ and the vaporization of different Fe phases during isothermal treatment. However, until now there is no detailed information about the composition and the remained amount of every Fe phases for thermal treated CCVD-derived MWCNTs.

In this study, the composition and the amount of the remained $\mathrm{Fe}$ catalysts have been investigated for isothermally treated CCVD-derived MWCNTs at various temperatures ranging from 900 to $2800{ }^{\circ} \mathrm{C}$ for different duration time from 2 to 60 minutes. Then, the effects of thermal treatment temperature and duration time on the removal of residual $\mathrm{Fe}$ catalysts are 
evaluated using X-ray fluorescence (XRF), ${ }^{57} \mathrm{Fe}$ transmission Mössbauer spectroscopy (TMS), X-ray diffraction (XRD) and transmission electron microscopy (TEM). Also, the removal process of Fe catalysts entrapped in MWCNTs is discussed kinetically.

\section{Experimental}

The carbon nanotubes used in this study were synthesized in a vertical tubular reactor by CVD-based floating reactant system using ferrocene and thiophene as catalyst precursor, toluene as carbon feedstock in a hydrogen atmosphere. Thermal treatment was carried out in a graphite-resistance furnace operating in a high-purity argon gas atmosphere in a semi-continuous system. The detailed synthesis and thermal treatment conditions have been described in detail in our former paper [23].

The residual amount of iron and sulfur was measured by X-ray fluorescence analysis (Rigaku ZSX mini) with $\mathrm{Pd} \mathrm{K}_{\alpha} \mathrm{X}$-ray source (the measurable limit is $30 \mathrm{ppm}$ for iron and $100 \mathrm{ppm}$ for sulfur). A JEOL X-ray diffractometer system (JDX-3532) was used to characterize the composition of impurity in carbon nanotubes with a $\mathrm{Cu} \mathrm{K}_{\alpha} \mathrm{X}$-ray source. In order to compare the absolute X-ray diffraction intensity for different samples, $40 \mathrm{mg}$ nanotubes were filled in a $25 \mathrm{~mm} \times 20 \mathrm{~mm} \times 1.5 \mathrm{~mm}$ sample holder. TEM observation (Hitachi HF-2200 Field Emission TEM) was also carried out to investigate the local information of catalyst particle in nanotubes. In addition, ${ }^{57} \mathrm{Fe}$ TMS was obtained with an Austin Science S-600 Mössbauer spectrometer using a $1.11 \mathrm{GBq}{ }^{57} \mathrm{Co} / \mathrm{Rh}$ source at room temperature. To ensure the signal strong enough in spite of the different iron content for various samples, the samples mounted in a holder $(18 \mathrm{~mm}$ in diameter, $50 \mathrm{~mm}$ in length) were weighting from 600 to $1500 \mathrm{mg}$. Curve fitting of the obtained spectra was performed with a personal computer, assuming that the spectra were composed of peaks in Lorentzian line shape. 


\section{Results and discussion}

3.1 Variation of the residual Fe catalysts during thermal treatment at different temperatures

In general, the composition of metallic catalysts entrapped in carbon nanotubes is characterized by TEM and XRD techniques. As shown in Fig. 1 (a), the catalyst particle could be observed at the tip of as-synthesized carbon tube. After thermally treated at $2000{ }^{\circ} \mathrm{C}$ for 20 minutes, the catalyst particle becomes disappeared without the disruption of tube morphology (Fig. 1 (b)). When the catalyst particle in tube is large enough, the structural information on metallic catalyst could be obtained with selected area electron diffraction analysis (the insert in Fig. 1 (a)). However, it is impossible for annealed tube after the catalyst particle disappeared (the insert in Fig1 (b)). Besides, the general information of Fe catalysts in our carbon nanotubes could be obtained in the range from 40 to $46^{\circ}$ from XRD profile. As shown in Fig. 2, there is a peak around $44.4^{\circ}$ for as-synthesized MWCNTs, but it disappears after tubes thermal treated above $2000^{\circ} \mathrm{C}$. Meanwhile, another peak around $43.4^{\circ}$ moves to around $42.6^{\circ}$, the location of $\mathrm{C}(100)$. These two peaks appearing around $44.4^{\circ}$ and $43.4^{\circ}$ for as-synthesized tubes are thought to originate from the residual $\mathrm{Fe}$ catalysts. After thermal treatment above $2000{ }^{\circ} \mathrm{C}$, the elimination of Fe catalysts is associated with the disappearance of the peak around $44.4^{\circ}$. While the peak around $43.4^{\circ}$ is overlapped by enhanced C (100) diffraction peak during thermal treatment, the situation is unclear. Thus the composition and the amount of Fe catalysts are difficult to evaluate because only indistinct peaks diffracted from the catalysts less than $10 \mathrm{~nm}$ are obtained, and there are so many peaks of $\mathrm{Fe}$ and its compounds with sulfur or carbon in the range from $44.4^{\circ}$ to $43.4^{\circ}$.

On the other hand, ${ }^{57} \mathrm{Fe}$ TMS at room temperature is known as the sensitive tool to detect the composition of iron phases entrapped in carbon nanotubes [24-26]. As shown in Fig. 3 (a), the

${ }^{57} \mathrm{Fe}$ TMS spectrum of the as-synthesized carbon nanotubes could be accurately separated into four different sets, indicating four different iron phases. Three sharp sets correspond to $\gamma$-iron, 
$\alpha$-iron and iron carbide, respectively. Considering that ferrocene and thiophene have been used as catalyst precursor in our nanotube synthesis, it is reasonable that the broad set is attributed to the spectral element of $\mathrm{Fe}_{1-\mathrm{x}} \mathrm{S}$ (pyrrhotite) with two crystal symmetries occurring together. The relative spectral areas corresponding to the four phases are $\gamma$-iron (8\%), $\alpha$-iron (15\%), $\mathrm{Fe}_{3} \mathrm{C}$ (20\%) and $\mathrm{Fe}_{1-\mathrm{x}} \mathrm{S}(57 \%)$. From the ${ }^{57} \mathrm{Fe}$ TMS spectrum of thermally treated MWCNTs at 1500 ${ }^{\circ} \mathrm{C}$ for 20 minutes (Fig. 3 (b)), the spectral signatures for $\gamma$-iron (13\%), $\alpha$-iron $(23 \%), \mathrm{Fe}_{3} \mathrm{C}$ $(64 \%)$ are fitted, but the spectral element corresponding to $\mathrm{Fe}_{1-\mathrm{x}} \mathrm{S}$ disappears completely. When MWCNTs were thermally treated at $2200{ }^{\circ} \mathrm{C}$ for 20 minutes, the ${ }^{57} \mathrm{Fe}$ TMS spectrum consists of $\gamma$-iron (2\%), $\alpha$-iron $(86 \%)$ and $\mathrm{Fe}_{3} \mathrm{C}(12 \%)$ (Fig. 3 (c)), indicating that the predominant component left in thermally treated carbon nanotubes at high temperature is pure Fe.

Utilizing the residual Fe content detected with XRF analysis and the relative spectral areas corresponding to each Fe phase fitted with ${ }^{57} \mathrm{Fe}$ TMS spectrum, the amount variation of each $\mathrm{Fe}$ phase as a function of thermal treatment temperatures is evaluated quantitatively. Obvious decrease of the total residual Fe content occurs between the range from 1800 to $2500{ }^{\circ} \mathrm{C}$ while there is little change above $2500{ }^{\circ} \mathrm{C}$ (Fig. 4 (a)). From 900 to $1200{ }^{\circ} \mathrm{C}$, the $\mathrm{Fe}_{1-\mathrm{x}} \mathrm{S}$ compound decreases a little, however it decreases abruptly in the range from 1200 to $1500{ }^{\circ} \mathrm{C}$ and disappears completely above $1500{ }^{\circ} \mathrm{C}$ (Fig. 4 (b)). On the contrary there are some increases in the relative amount of $\mathrm{Fe}_{3} \mathrm{C}$ phase in the temperature range of $1200-1500{ }^{\circ} \mathrm{C}$ (Fig. 4 (c)), while both the pure metallic $\gamma$-iron and the $\alpha$-iron show little variation in the same temperature range (Fig. 4 (d) and (e)). In the range from 1500 to $2400{ }^{\circ} \mathrm{C}, \mathrm{Fe}_{3} \mathrm{C}$ phase decreases continuously and vanishes above $2400{ }^{\circ} \mathrm{C}$. Similarly the relative amount of $\gamma$-iron has obviously decreased in the range from 1500 to $2400{ }^{\circ} \mathrm{C}$, while the amount of $\alpha$-iron show down trend in the range from 2000 to $2600{ }^{\circ} \mathrm{C}$. Above $2400^{\circ} \mathrm{C}$, the residual Fe component only consists of pure metal phases $(\gamma$-iron and $\alpha$-iron). 
Considering the result mentioned above, the removal process of residual $\mathrm{Fe}$ catalysts in our MWCNTs can be described as following. The $\mathrm{Fe}_{1-\mathrm{x}} \mathrm{S}$ compound decomposes at first in the range from 1200 to $1500{ }^{\circ} \mathrm{C}$ and finally vanishes above $1500{ }^{\circ} \mathrm{C}$. In the same temperature range, little reduction is observed for the total Fe content and the pure metal iron phase, on the contrary there is some increase in the relative amount of $\mathrm{Fe}_{3} \mathrm{C}$ phase. It indicates that the main variation of $\mathrm{Fe}$ catalysts in this temperature range $\left(1200-1500^{\circ} \mathrm{C}\right)$ is the decomposition of $\mathrm{Fe}_{1-\mathrm{x}} \mathrm{S}$ compound. The decomposed sulfur vaporizes rapidly while the decomposed iron element is carbonized into $\mathrm{Fe}_{3} \mathrm{C}$ compound, rather than vaporization, because the temperature is still below the vaporization temperature of iron. In the temperature range from 1500 to $1800{ }^{\circ} \mathrm{C}$, obvious reduction is detected for carbide $\mathrm{Fe}_{3} \mathrm{C}$ phase however there is little change of total $\mathrm{Fe}$ content. It indicates that in the range of $1500-1800^{\circ} \mathrm{C}$ the main variation is the decomposition of carbide $\mathrm{Fe}_{3} \mathrm{C}$ phase. In the temperature range from 1800 to $2400{ }^{\circ} \mathrm{C}$, obvious reduction for carbide $\mathrm{Fe}_{3} \mathrm{C}$ phase, pure iron phase and total Fe content reveals that not only the decomposition of carbide $\mathrm{Fe}_{3} \mathrm{C}$ phase but also the vaporization of all iron phase occur surely. Above $2400{ }^{\circ} \mathrm{C}$, there is no carbide $\mathrm{Fe}_{3} \mathrm{C}$ phase left that means the $\mathrm{Fe}_{3} \mathrm{C}$ phase has decomposed completely. The elimination of residual $\mathrm{Fe}$ is the vaporization of pure Fe. However several hundreds ppm of pure $\mathrm{Fe}$ is found even after thermally treating at $2800{ }^{\circ} \mathrm{C}$ for 20 minutes.

\subsection{Isothermal evaluation of the removal process of $\mathrm{Fe}$ catalysts}

To evaluate the Fe catalyst removal process isothermally, isothermal treatment was carried out with duration times varied from 2 to 60 minutes at 1800,2000 and $2400{ }^{\circ} \mathrm{C}$. As shown in Fig. 5 (a), the residual iron content (denoted as $\mathrm{C}$ value) decreases continuously with the duration time at both 1800 and $2000{ }^{\circ} \mathrm{C}$, while it exhibit little change for thermally treated sample at $2400{ }^{\circ} \mathrm{C}$ for duration time more then 20 minutes. As mentioned above, most of the residual catalytic Fe could be eliminated by thermally treating our nanotubes at $2400{ }^{\circ} \mathrm{C}$ for more than 20 minutes. 
Therefore it is suitable to discuss the removal process of Fe catalysts isothermally with the content of residual iron in the variation ranges. Plots of the $\ln (\mathrm{C}$ value $)$ versus isothermal thermal treatment duration time at 1800 and $2000{ }^{\circ} \mathrm{C}$ from 2 to 60 minutes, $2400{ }^{\circ} \mathrm{C}$ from 2 to 10 minutes, shows the linear relationship, which enable us to get the rate constant $k$ at each thermal treatment temperature from the slopes of these lines as shown in Fig. 5 (b) $(k=d \ln (C$ value)/dt). By applying Arrhenius equation written as in following [27], the apparent activation energy for removal of Fe catalyst in MWCNTs could be estimated.

$\mathrm{k}=\mathrm{A} \exp (-\mathrm{E} / \mathrm{RT})$

In the Arrhenius equation, $\mathrm{k}$ is the rate constant, $\mathrm{E}$ the energy of activation, $\mathrm{A}$ the frequency factor, $\mathrm{T}$ the absolute temperature of heat treatment and $\mathrm{R}$ is the gas constant. The resultant linear relation of the plot $\ln (\mathrm{k})$ as a function of $1 / \mathrm{T}$ (Fig. 5 (c)) provides the estimation of the apparent activation energy as the order of $76 \mathrm{kcal} / \mathrm{mol}$ for elimination of metallic catalyst entrapped in our thermally treated MWCNTs in the range from 1800 to $2400^{\circ} \mathrm{C}$. This value is significantly corresponding to the activation energy for self-diffusion of Fe element: 68 $\mathrm{kcal} / \mathrm{mol}$ at melting point $(1811 \mathrm{~K})[28]$. Therefore, it is important to note that $\mathrm{Fe}$ compounds entrapped in carbon nanotubes are removed via a diffusion process, instead of phase transformation, although there are several phases of iron catalysts in our nanotubes. In the other word, the residual Fe catalysts in tubes could move transfer to the outer surface of carbon nanotubes diffusively by heat treatment.

\section{Conclusions}

The residual Fe catalysts in our CCVD-derived MWCNTs have been characterized including the variation of both the composition and the remained content during isothermal treatment. Based on Mössbauer studies, there are four iron phases in as-synthesized MWCNTs, and their relative amounts are $8 \%$ of $\gamma$-iron, $15 \%$ of $\alpha$-iron, $20 \%$ of $\mathrm{Fe}_{3} \mathrm{C}$ and $57 \%$ of $\mathrm{Fe}_{1-\mathrm{x}} \mathrm{S}$. The $\mathrm{Fe}_{1-\mathrm{x}} \mathrm{S}$ 
compound decomposes completely around $1500{ }^{\circ} \mathrm{C}$. The decomposed sulfur vaporizes rapidly while the decomposed iron element converted to iron carbide. The noticeable decrease in the total amount of the remained $\mathrm{Fe}$ occurs in the temperature range above $1800^{\circ} \mathrm{C}$. At $2400{ }^{\circ} \mathrm{C}$, there is no carbide $\mathrm{Fe}_{3} \mathrm{C}$ phase left that means the $\mathrm{Fe}_{3} \mathrm{C}$ phase has decomposed completely. By thermally treating above $2400{ }^{\circ} \mathrm{C}$, we could obtain high purity carbon nanotubes with small amount of pure Fe. As determined in a previous study of toxic evaluation [29], our thermally treated tubes showed relatively inert biological reactivity. Also, the estimated apparent activation energy regarding the removal of Fe catalyst for thermally treated samples in the range from 1800 to $2400{ }^{\circ} \mathrm{C}$ is ca. $76 \mathrm{kcal} / \mathrm{mol}$, indicating that the entrapped Fe compounds in carbon nanotubes are eliminated via a diffusion process during isothermal annealing.

\section{Acknowledgements}

This work was supported by a Grant-in-Aid from the Ministry of Education, Culture, Sports, Science and Technology of Japan (No. 18710084) and the CLUSTER (the second stage) of Ministry of Education, Culture, Sports, Science and Technology of Japan. 


\section{References}

[1] Oberlin A, Endo M, Koyama T. Filamentous growth of carbon through benzene decomposition. J Cryst Growth 1976; 32: 335-49.

[2] Iijima S. Helical microtubules of graphitic carbon. Nature 1991; 354: 56-8.

[3] Dresselhaus MS, Dresselhaus G., Eklund PC. Science of fullerenes and carbon nanotubes. San Diego: Academic Press; 1996. p. 756-864.

[4] Saito R, Dresselhaus MS, Dresselhaus G. Physical properties of carbon nanotubes. London: Imperial College Press; 1998.

[5] Hone J, Llaguno MC, Biercuk MJ, Johnson AT, Batlogg B, Benes Z, et al. Thermal properties of carbon nanotubes and nanotube-based materials. Appl Phys A: Mater Sci Process 2002; 74: 339-43.

[6] Krishnan A, Dujardin E, Ebbesen TW, Yianilos PN, Treacy MMJ. Young's modulus of single-walled nanotubes. Phys Rev B 1998; 58: 14013-9.

[7] Demczyk BG, Wang YM, Cumings J, Hetman M, Han W, Zettl A, et al. Direct mechanical measurement of the tensile strength and elastic modulus of multiwalled carbon nanotubes. Mater Sci Eng A: Struct Mater Properties Microstruct Process. 2002; 334: 173-8.

[8] Wei BQ, Vajtai R, Ajayan PM. Reliability and current carrying capacity of carbon nanotubes. Appl Phys Lett 2001; 79: 1172-4.

[9] Durko T, Getty SA, Cobas E, Fuhrer MS. Extraordinary mobility in semiconducting carbon nanotubes. Nano Lett 2004; 4: 35-9.

[10] Baughman RH, Zakhidov AA, De Heer WA. Carbon nanotubes--the route toward applications. Science 2002; 297: 787-92.

[11] Endo M. Grow carbon fibers in the vapor phase. Chem Tech 1988; 18:568-576.

[12] Tibbetts GG, Bernnardo CA, Gorkiewicz DW, Alig RL. Effect of sulfur on the production 
of carbon fibers in the vapor phase. Carbon 1994; 32:569-576.

[13] Kim YA, Hayashi T, Endo M, Kaburagi Y, Tsukada T, Shan JY, et al. Synthesis and structural characterization of thin multi-walled carbon nanotubes with a partially facetted cross section by a floating reactant method. Carbon 2005;43:2243-50.

[14] Collins S, Brydson R, Rand B. Structural analysis of carbon nanofibers grown by the floating reactant method. Carbon 2002; 40:1089-1100.

[15] Service RF. Nanotubes: the next asbestos? Science 1998; 281:941.

[16] Service RF. Nanomaterials show signs of toxicity. Science 2003; 300:243.

[17] Dreher KL. Health and environmental impact of nanotechnology: toxicological assessment of manufactured nanoparticles. Toxicological sciences 2004; 77:3-5.

[18] Hurt RH, Monthioux M, Kane A. Toxicology of carbon nanomaterials: Status, trends, and perspectives on the special issue. Carbon 2006; 44: 1028-33.

[19] Uo M, Watari F, Yokoyama A, Matsuno H, Kawasaki T. Tissue reaction around metal implants observed by X-ray scanning analytical microscopy. Biomaterials 2001; 22: $677-85$.

[20] McNamara A, Williams DF. The response to the intramuscular implantation of pure metals. Biomaterials 1981; 2: 33-40.

[21] Endo M, Kim YA, Hayashi T, Nishimura K, Matushita T, Miyashita K, et al. Vapor grown carbon fibers (VGCFs): Basic properties and their battery applications. Carbon 2001;39: 1287-97.

[22] Andrews R, Jacques D, Qian D, Dickey EC. Purification and structural annealing of multiwalled carbon nanotubes at graphitization temperatures. Carbon 2001;39: 1681-7.

[23] Chen J, Shan JY, Tsukada T, Munekane F, Kuno A, Matsuo M, et al. The structural evolution of thin multi-walled carbon nanotubes during isothermal annealing. Carbon 
2007;45: 274-280.

[24] Marco JF, Gancedo JR, Hernando A, Crespo P, Prados C, Gonzalez JM, et al. Mössbauer study of iron-containing carbon nanotubes. Hyperfine Interactions 2002;139/140: 535-42.

[25] Coquay P, De Grave E, Vandenberghe RE, Peigney A, Laurent CH. Mössbauer spectroscopy involved in the study of the catalyst growth of carbon nanotubes. Hyerfine Interactions. 2002;139/140:289-96.

[26] Ruskov T, Asenov S, Spirov I, Garcia C. Mössbauer transmission and back scattered conversion electron study of Fe nanowires encapsulated in multiwalled carbon nanotubes. $\mathrm{J}$ Appl Phys 2004; 96(12):7514-8.

[27] Brown WE, Dollimore D, Galwey AK. Reactions in the solid state. In: editors Bamford CH and Tipper CFH, Chemical Kinetics, Vol. 22, Elsevier;New York, 1980.

[28] Glicksman ME. Diffusion in solids: field theory, solid-state principles, and applications. John Wiley \& Son; 2000. p. 245-263.

[29] Koyama S, Endo M, Kim YA, Hayashi T, Yanagisawa T, Osaka K, et al. Role of systemic T-cells and histopathological aspects after subcutaneous implantation of various carbon nanotubes in mice. Carbon 2006; 44:1079-92. 


\section{Figure captions}

Figure 1 TEM images of the tips of (a)as-synthesized and (b) $2000{ }^{\circ} \mathrm{C}$ annealed MWCNTs for 20 minutes. Insets are their corresponding selected area electron diffraction patterns.

Figure 2 X-ray diffraction patterns of as-synthesized and thermally treated MWCNTs at different temperatures.

Figure $3{ }^{57} \mathrm{Fe}$ Transmission Mössbauer spectra for (a) as-synthesized carbon nanotubes, and thermally treated carbon nanotubes at (b) $1500{ }^{\circ} \mathrm{C}$ and (c) $2200{ }^{\circ} \mathrm{C}$, respectively.

Figure 4 Changes in the relative amount of iron related compounds as the function of temperature for (a) total Fe content measured with XRF, (b) $\mathrm{Fe}_{1-\mathrm{x}} \mathrm{S}$, (c) $\mathrm{Fe}_{3} \mathrm{C}$, (d) $\gamma$-Fe, and (e) $\alpha$-Fe, deduced from the results of ${ }^{57} \mathrm{Fe}$ TMS and XRF.

Figure 5 Changes in (a) the residual iron content measured with XRF (denoted as $\mathrm{C}$ value) and (b) $\ln (\mathrm{C}$ value $)$ for samples heat treated at 1800,2000 and $2,400{ }^{\circ} \mathrm{C}$ as the function of duration time, and (c) plot of $\ln [\operatorname{dn}(\mathrm{C}$ value $) / \mathrm{dt}]$ versus $1 / \mathrm{T}$, the estimation of activation energy for the elimination of Fe catalysts in the temperature range from 1800 to $2400{ }^{\circ} \mathrm{C}$. 
Fig.1
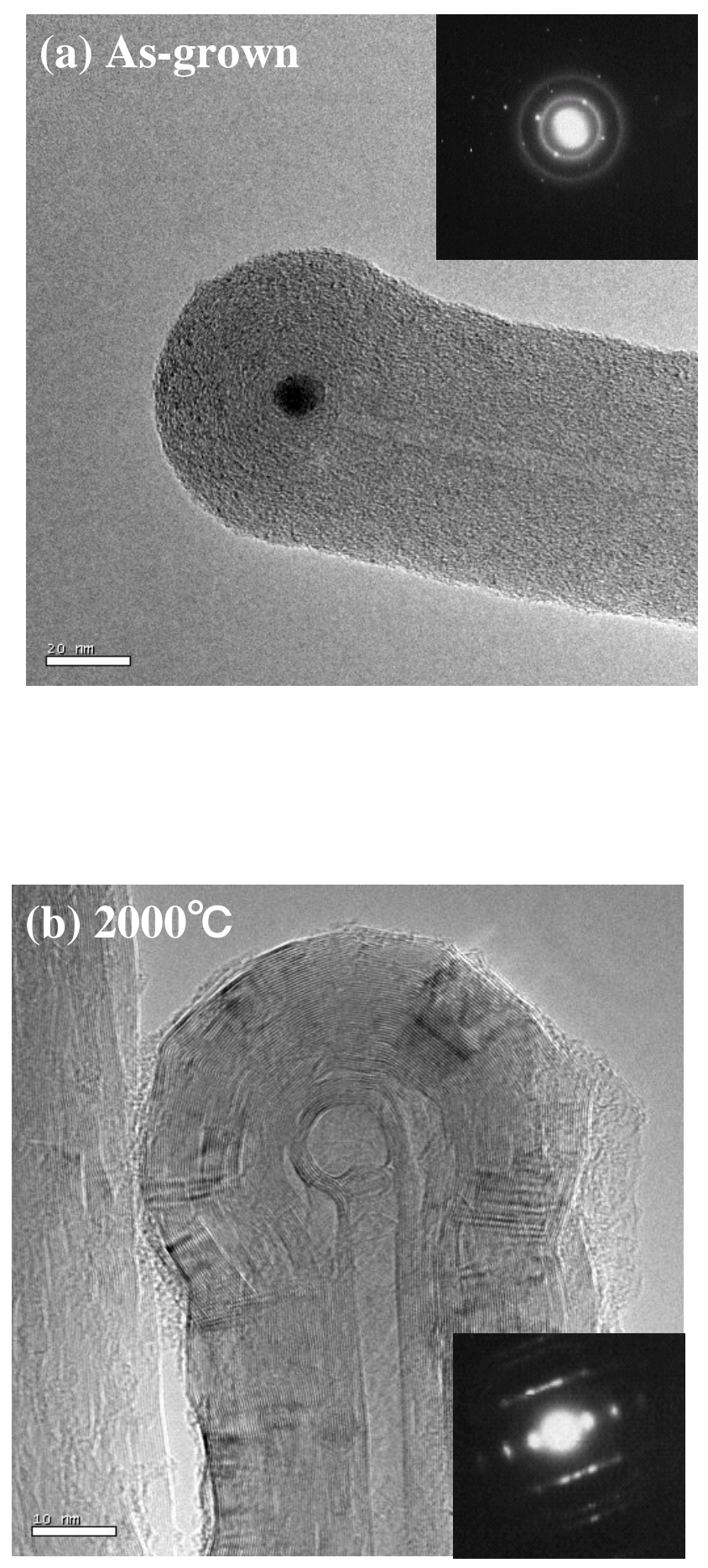


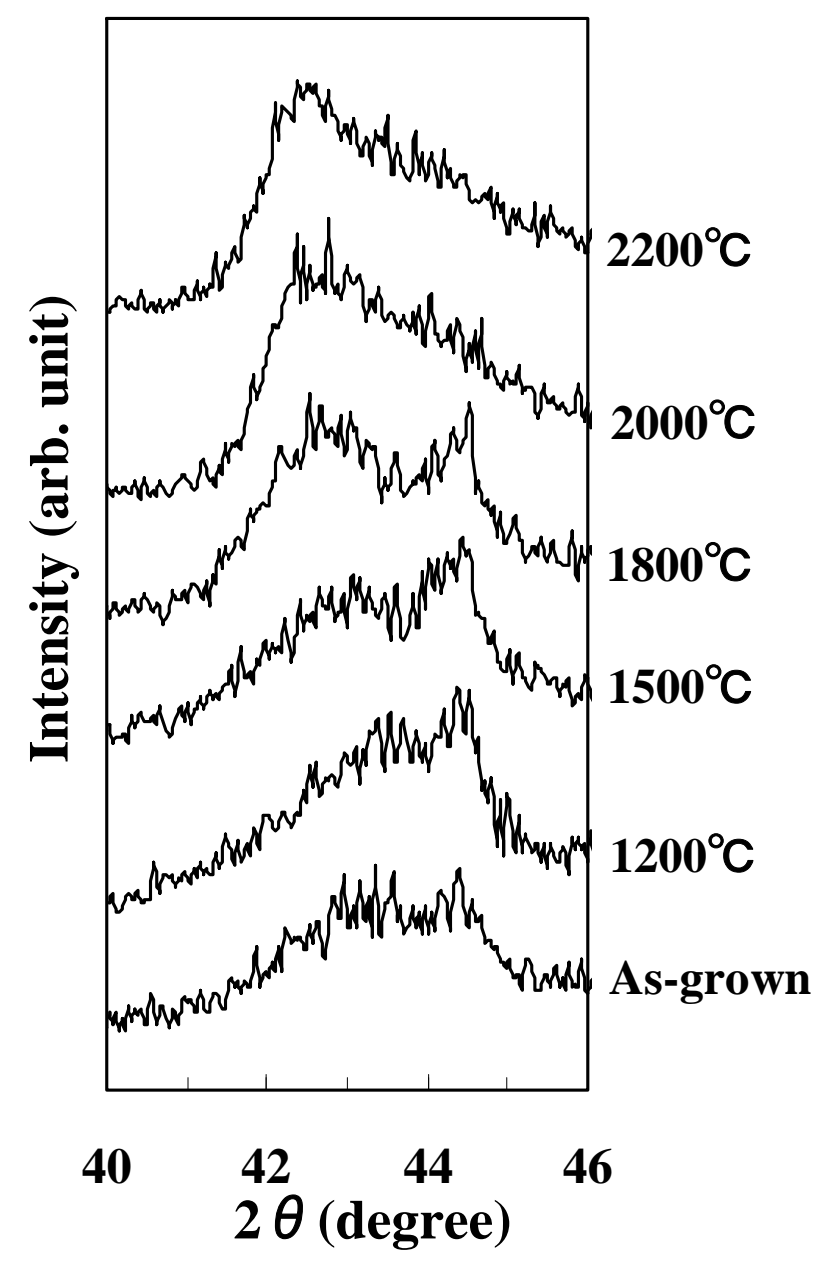


Fig.3

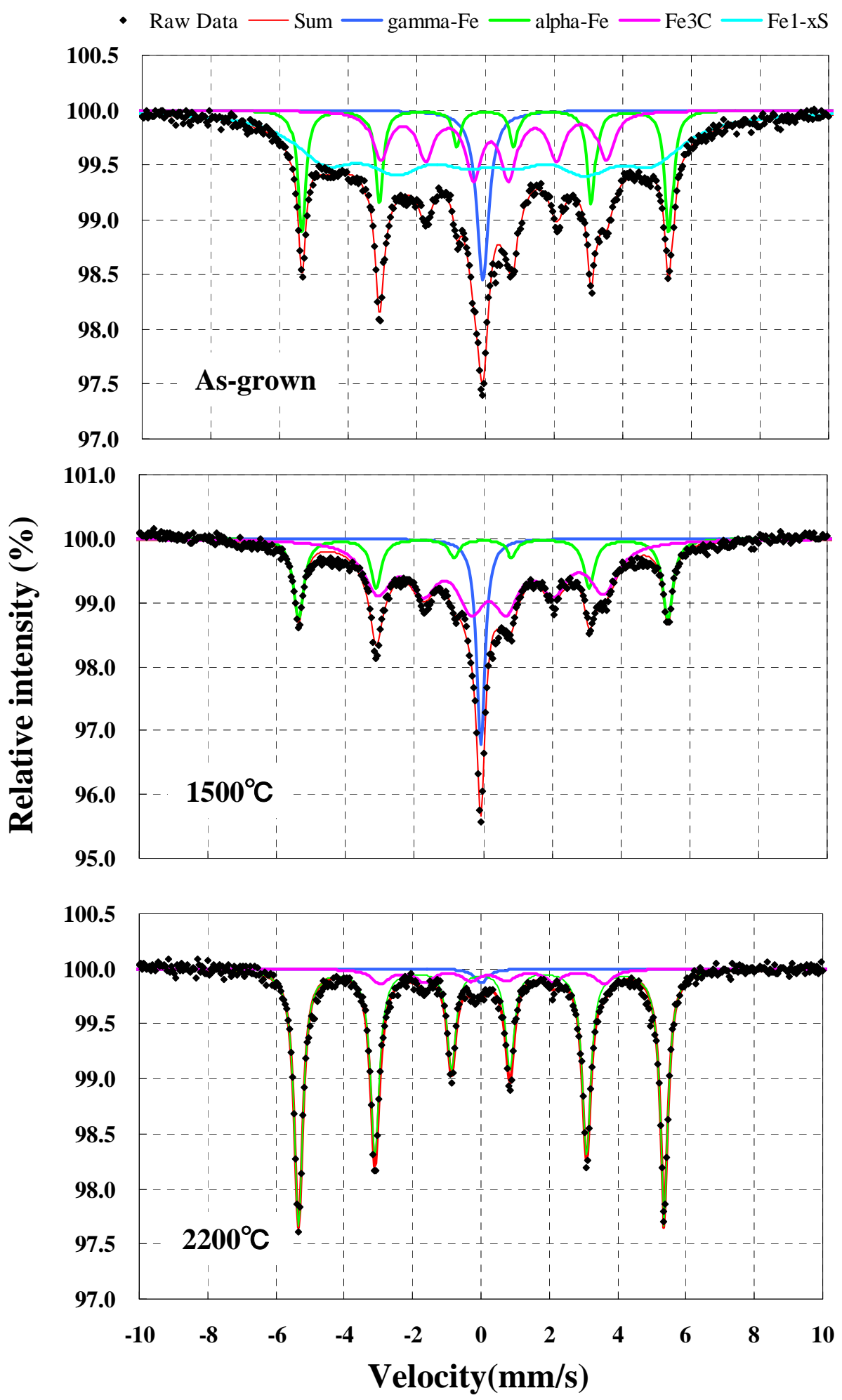


Fig.4

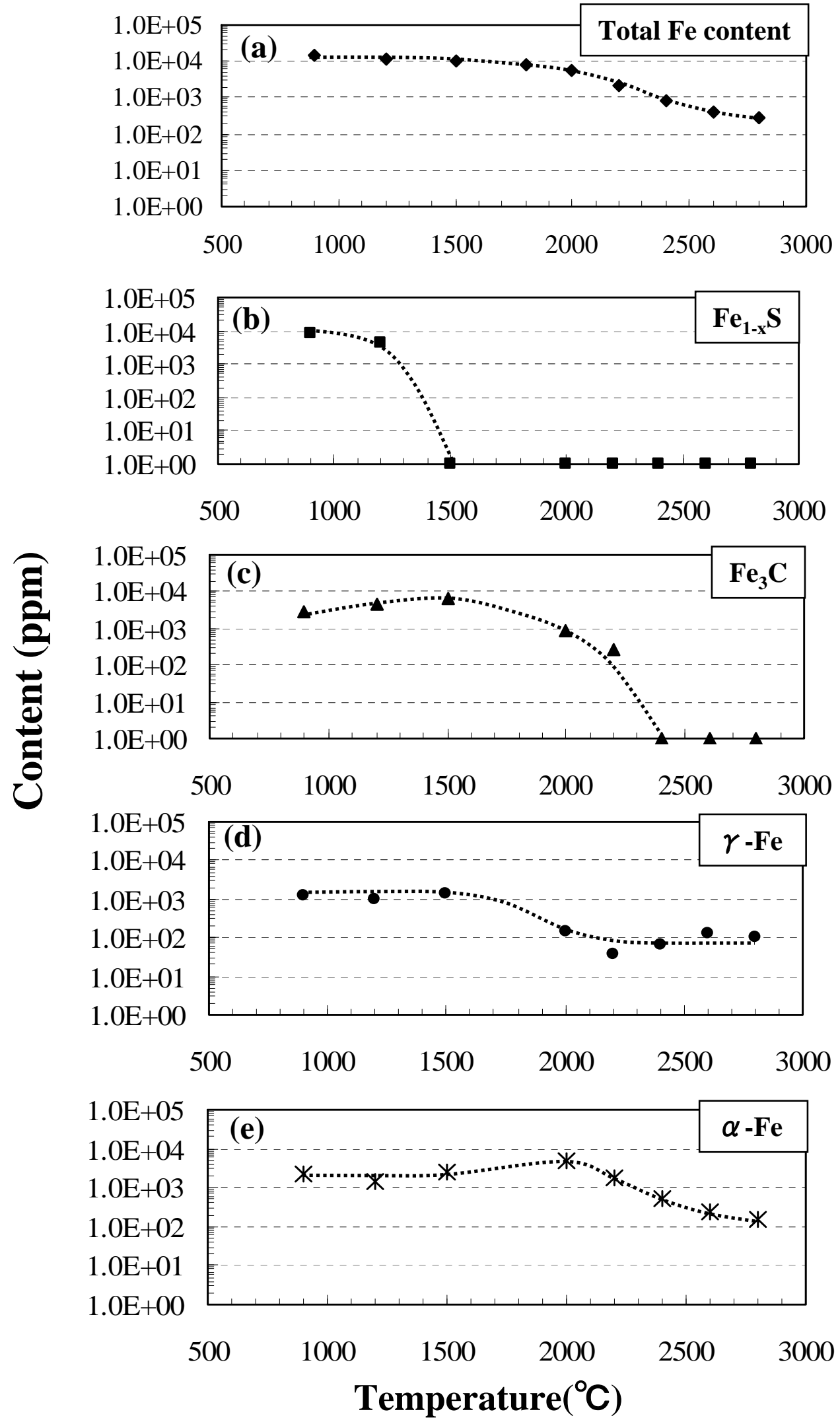


Fig.5

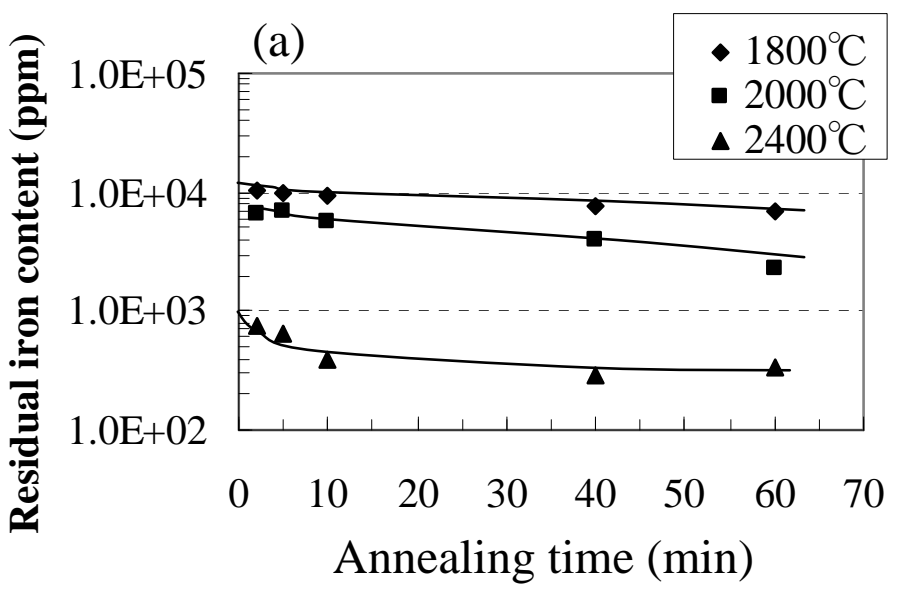

(b)
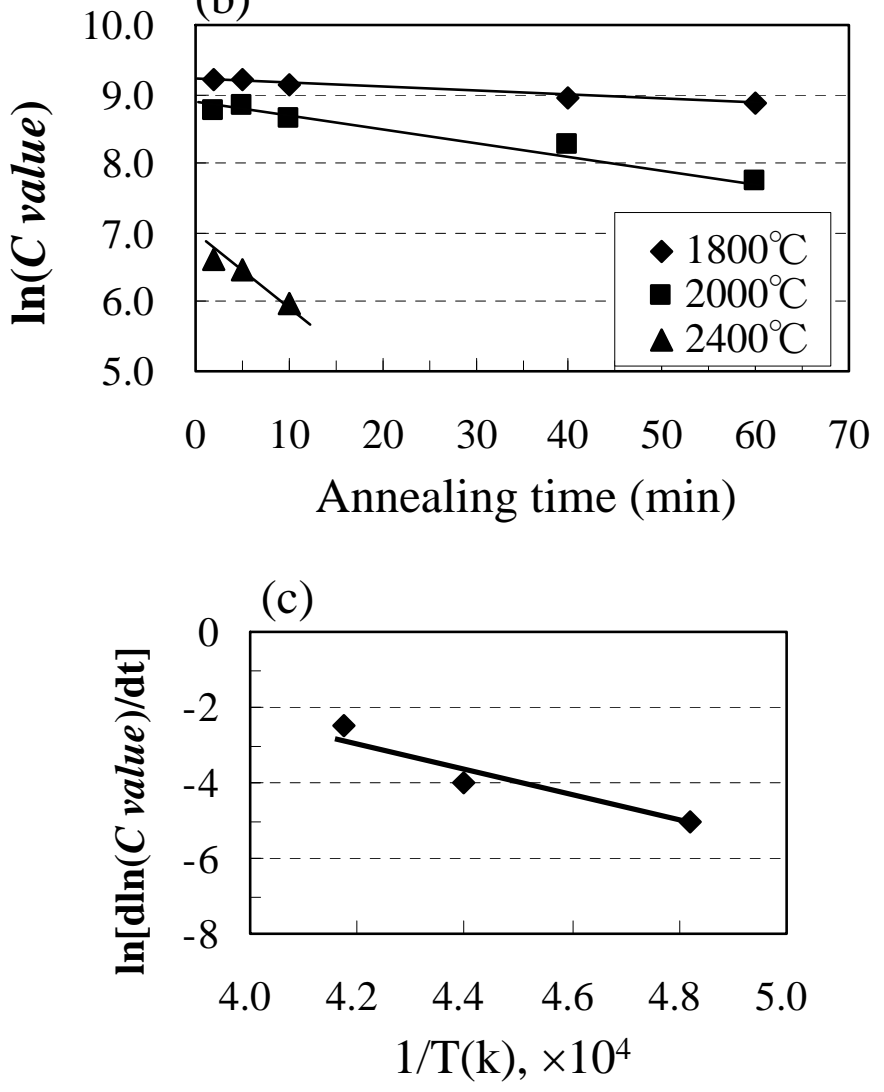